\title{
Performance Evaluation of Groundnut Varieties in Eastern Parts of Ethiopia
}

\author{
Habte Berhanu, Adugna Hunduma, Motuma Dalasa and Abebe Getachew \\ Oromia Agricultural Research Institute (IQQO), Fedis Agricultural research center, P.O. Box: 904, Harar, \\ Ethiopia
}

\begin{abstract}
Groundnut plays an important role as a food as well as cash crop in Ethiopia. Its production in Ethiopia is found to be constrained by several biotic and abiotic factors. To this end, this study was done with the objective of identifying the high yielding, biotic and abiotic resistance or tolerance varieties in 2019. A total of six varieties were evaluated in RCBD. AMMI showed that environments, varieties and their interaction effects were significantly different. The stability and high yielding ability of the varieties has been graphically depicted by the AMMI bi-plot. The variation for seed yield among the varieties for each variety was significant at different environments. Varieties G1 (Bulki), G6 (Babile2) and G4 (Werer962) were specifically adapted to high yielding environments. G2 (Shulamiz) was the most unstable variety. G1 (Bulki) was more stable in comparison to other varieties. In GGE bi-plot; IPCA 1 and IPCA $_{2}$ explained $48.07 \%$ and $25.93 \%$, respectively, of groundnut variety by environment interaction and made a total of $74.00 \%$ of variation. Therefore, Bulki $\left(1075 \mathrm{~kg} \mathrm{ha}^{-1}\right)$ and Babile2 $\left(1030 \mathrm{~kg} \mathrm{ha}^{-1}\right)$ were most stable recommended for the study area and similar agro-ecologies and Fedis was the ideal environment for groundnut production.
\end{abstract}

Keywords: AMMI, G x E interaction, Groundnut

DOI: $10.7176 / \mathrm{FSQM} / 102-04$

Publication date: November $30^{\text {th }} 2020$

\section{Introduction}

Groundnut (Arachis hypogaea L.) plays an important role as a food as well as a cash crop in Ethiopia (Dereje A. et al., 2012). Currently the crop is becoming one of the high value crops that are growing in the lowlands areas of the eastern Oromia. Groundnut, or peanut, is commonly called the poor man's nut. Today it is an important oilseed and food crop (FAO, 2002). Groundnuts are produced in the tropical and subtropical regions of the world, on sandy soils.

In Ethiopia, groundnut is cultivated predominantly by the traditional and undeveloped farming community under rain-fed conditions. It occupies about 79,947 hectares of land with a corresponding gross annual production of about 1128,887 qt. (CSA, 2013/14). The yields of groundnut in Ethiopia compared to other countries are very low i.e. below 1.1 ton $\mathrm{ha}^{-1}$ as compared to average yields on a global scale i.e. 1.52 ton ha ${ }^{-1}$ but with good management practices, yields can be increased to 3.0 ton ha-1 (CSA, 2009; FAOSTAT, 2009). Groundnut production in Ethiopia is found to be constrained by several biotic and abiotic factors i.e. critical moisture stress especially during flowering and then after, lack of improved varieties and appropriate production and post-harvest practices, and diseases affecting both above- and underground parts of the plant (Alemeyehu C. et al., 2014).

Objective of the study was;-

$>$ To evaluate and recommend the best high yielding and early matured varieties in study areas.

\section{Materials and Methods}

This activity has been conducted at Fedis on station. A total of seven recently released varieties of groundnut were collected from BARC and one local check was used as planting materials. The experiment was arranged in RCBD. The varieties were grown under uniform rain fed conditions. The experimental plots consisted of six rows of $3 \mathrm{~m}$ length, $3.6 \mathrm{~m}$ width and $0.6 \mathrm{~m}$ row space. The central four rows were harvested to estimate grain yield. The spacing between adjacent replications and plots were $1 \mathrm{~m}$, and $1 \mathrm{~m}$, respectively. Important data like: - date of emergency, date of flowering, plant height, pod per plants, seed per pod, numbers of branches per plants and yielded per plots were collected.

Days to flowering: The number of days from date of emergence to the stage where $75 \%$ of the flower have fully opened.

Days to maturity: The number of days from date of emergence to the stage when $90 \%$ the plants in a plot have reached physiological maturity.

Pods per plant: This was recorded by mean number of pods obtained from ten randomly taken plants at harvest

Seeds per pod: Mean numbers of seeds obtained from five plants were selected at random from each plot and the total number of seeds was counted, the average was calculated and recorded as the number of seeds per plant.

Grain yield per hectare: Grain yield obtained from each experimental plot and converted to grain yield per hectare and corrected to $13 \%$ humidity 


\section{Result and Discussion}

\section{Combined Analysis of Variance}

Analysis of variance was carried out to determine the effects of varieties, location and their interaction on seed yield of groundnut varieties. Accordingly, Environment and Genotype for seed yield showed statistically highly significant differences $(\mathrm{P}<0.01)$ indicating the presence of genetic variation and possible selection of high yielding and stable varieties (Table 1). This indicates the big influence of environment and varieties on yield performance of groundnut varieties. The significant effect of environments indicated that the testing environments were significantly different from each other for expressing their yield potential. Similarly, Sunday C. et al., (2013) reported the different performance of genotypes across environments could also be indicative of wide variation in climatic conditions and soil types in the different growing environments. The mean yield potential of the varieties varying across environments and among varieties indicating the varieties were expressing their potentials even though they were affected by environments and genetic variations.

Table 1. Analysis of variance for seed yield of Groundnut varieties evaluated across two years for different locations.

\begin{tabular}{ccc}
\hline Source of variation & d.f. & mean square \\
\hline Block & 2 & 3.75 \\
Genotypes & 7 & $11.667^{*}$ \\
Environment & 5 & $154.47^{* *}$ \\
Interaction & 35 & 7.083 \\
Error & 94 & 5.081 \\
Total & 143 & \\
\hline
\end{tabular}

\section{Mean seed yield of groundnut varieties evaluated at six environments}

The average environmental seed yield across varieties ranged from the lowest of 6.44 Qtha $^{-1}$ at E2 (Erer 2017) to the highest of 12.85 Qtha ${ }^{-1}$ at E1 (Fadis 2017), with a grand mean of 9.59 Qtha ${ }^{-1}$ (Table 2). The varieties average seed yield across environments ranged from the lowest of $8.06 \mathrm{Qtha}^{-1}$ for Shumaliz to the highest of $10.75 \mathrm{Qtha}^{-1}$ for Bulki (Table 2). This difference could be due to their genetic potential of the varieties and also environment explained large variation indicated the existence of diverse mega environments.

Table 2: Mean seed yield (Qt/ha) of groundnut varieties evaluated at six environments

\begin{tabular}{|c|c|c|c|c|c|c|c|}
\hline \multirow[b]{2}{*}{ Varieties } & \multirow[b]{2}{*}{$\begin{array}{c}\text { E1(Fadis } \\
\text { 2017) }\end{array}$} & \multicolumn{4}{|c|}{ Mean of seed yield across environment } & \multirow[b]{2}{*}{$\begin{array}{c}\text { E6(Qile } \\
\text { 2019) }\end{array}$} & \multirow[b]{2}{*}{ mean } \\
\hline & & $\begin{array}{c}\text { E2(Erer } \\
\text { 2017) }\end{array}$ & $\begin{array}{c}\text { E3(Fadis } \\
\text { 2018) }\end{array}$ & $\begin{array}{c}\text { E4(Dire } \\
2018)\end{array}$ & $\begin{array}{c}\text { E5(Qile } \\
2018)\end{array}$ & & \\
\hline Bulki & 10.99 & 7.23 & 11.73 & 9.50 & 16.20 & 8.88 & $10.75 \mathrm{a}$ \\
\hline Shumaliz & 12.46 & 6.61 & 9.04 & 4.27 & 8.60 & 7.38 & $8.06 \mathrm{c}$ \\
\hline Werer961 & 14.17 & 5.32 & 14.06 & 5.75 & 9.05 & 7.05 & $9.23 \mathrm{bc}$ \\
\hline Werer962 & 13.56 & 6.37 & 13.03 & 9.05 & 9.25 & 7.69 & $9.83 \mathrm{ab}$ \\
\hline Roba & 14.22 & 7.16 & 10.94 & 7.36 & 9.81 & 8.78 & $9.71 \mathrm{ab}$ \\
\hline Babile2 & 12.68 & 6.72 & 12.96 & 11.18 & 9.46 & 8.79 & $10.30 \mathrm{ab}$ \\
\hline Baha Jiddu & 13.33 & 6.57 & 12.73 & 7.86 & 9.08 & 8.04 & $9.60 \mathrm{ab}$ \\
\hline Local Variety & 11.42 & 5.56 & 12.30 & 8.62 & 9.57 & 7.84 & $9.22 b c$ \\
\hline Mean & 12.85 & 6.44 & 12.10 & 7.95 & 10.13 & 8.06 & 9.59 \\
\hline
\end{tabular}

\section{Additive Main Effects and Multiple Interaction (AMMI) model}

AMMI analysis of variance for Seed yield of eight groundnut varieties tested in six environments showed that environments, varieties and their interaction effects were significantly different $(\mathrm{P}<0.01)$ (Table 3 ) demonstrating the importance of applying AMMI analysis to investigate the main effects of varieties and environment and the complex patterns of their interaction. The environment modeled significant effect on the seed yield of groundnut, which explained $48.67 \%$ of the total variation indicating the existence of a considerable amount of deferential response among the varieties to changes in growing environments and the differential discriminating ability of the test environments. GEI contribute $15.62 \%$ of total variation while the Varieties contribute only $5.15 \%$ of the total variation. Similarly, Amare Kebede and Adisu Getahun (2017) reported the analysis of variance showed genotype (8.8\%), environment (69.8\%), and GEI $(21.4 \%)$ effects were significant $(\mathrm{P}<0.01)$. 
Table 3. Partitioning of the Explained Sum of square (Ex.SS) and Mean of square (MS) from AMMI analysis for seed yield of eight groundnut varieties evaluated at six environments

\begin{tabular}{ccccc}
\hline Source of variation & d.f. & Sum square & Ex Sum square & Mean square \\
\hline Total & 143 & 1587.1 & 100 & 11.1 \\
Treatments & 47 & 1101.9 & 69.43 & $23.45^{* *}$ \\
Genotypes & 7 & 81.7 & 5.15 & $11.67^{* *}$ \\
Environments & 5 & 772.4 & 48.67 & $154.47^{* *}$ \\
Block & 12 & 174.3 & 10.98 & $14.53^{* *}$ \\
Interactions & 35 & 247.9 & 15.62 & $7.08^{* *}$ \\
IPCA 1 & 11 & 136.1 & 8.58 & $12.37^{* *}$ \\
IPCA 2 & 9 & 74.3 & 4.68 & $8.25^{*}$ \\
Error & 15 & 37.5 & 2.36 & 2.5 \\
Pooled Error & 84 & 310.8 & 19.58 & 3.7
\end{tabular}

As reported by Purchase et al., 2000, genotype with least ASV score is the most stable varieties. Accordingly, Bulki and Babile2 were most stable and Werer961 and Baha Jiddu were the most unstable. This measure is essential in order to quantify and rank varieties according to their seed yield stability. The least Genotype Selection Index (GSI) is considered as the most stable with high grain yield (Hagos et al., 2011). Based on the GSI, the most desirable variety for selection of both stability and high seed yield was Bulki followed by Babile2.

Table 4. IPCA 1, IPCA $_{2}$ scores, AMMI stability value and Genotype Selection Index of eight groundnut varieties

\begin{tabular}{ccccccc}
\hline Variety & Mean yield & RYi & IPCA1 & IPCA2 & ASVi & RASVi \\
\hline Bulki & 10.754 & 1 & -2.28129 & 0.2415 & 0.933 & 7 \\
Shumaliz & 8.06 & 8 & 0.23873 & 1.42978 & 1.80 & 3 \\
Werer961 & 9.233 & 6 & 0.95733 & 0.24238 & 3.533 & 8 \\
Werer962 & 9.826 & 3 & 0.43839 & -0.56141 & 2.067 & 5 \\
Roba & 9.713 & 4 & 0.29972 & 0.69252 & 2.867 & 6 \\
Babile2 & 10.301 & 2 & 0.04194 & -1.23832 & 1.733 & 2 \\
Baha Jiddu & 9.601 & 5 & 0.48956 & -0.11966 & 3.40 & 1 \\
Local Variety & 9.217 & 7 & -0.18438 & -0.68679 & 1.933 & 4 \\
\hline
\end{tabular}

The stability and high yielding ability of the varieties has been graphically depicted by the AMMI bi-plot. Environments E3 (Fadis 2018) and E1 (Fadis 2017) relatively showed high IPCA scores, contributed largely to GEI. These environments were favorable for high yielding varieties based on mean yield as they had more than the grand mean. Environment E2 (Erer 2017) is the least favorable environment for almost all the varieties with low yield and smaller IPCA 1 score (Fig 1).

The variation of yield for each variety was significant at different environments. Varieties G1 (Bulki), G6 (Babile2) and G4 (Werer962) were specifically adapted to high yielding environments (Fig 2). Considering the IPCA1 score, G2 (Shulamiz) was the most unstable variety and also adapted to higher yielding environments. G1 (Bulki) was more stable in comparison to other varieties. Generally, Fadis was the most favorable environment for ground nut production with maximum mean of yield potential. 
Figure 1: Biplot of interaction principal component axis $\left(\mathrm{IPCA}_{1}\right)$ against mean Seed yield of eight groundnut varieties and six environments

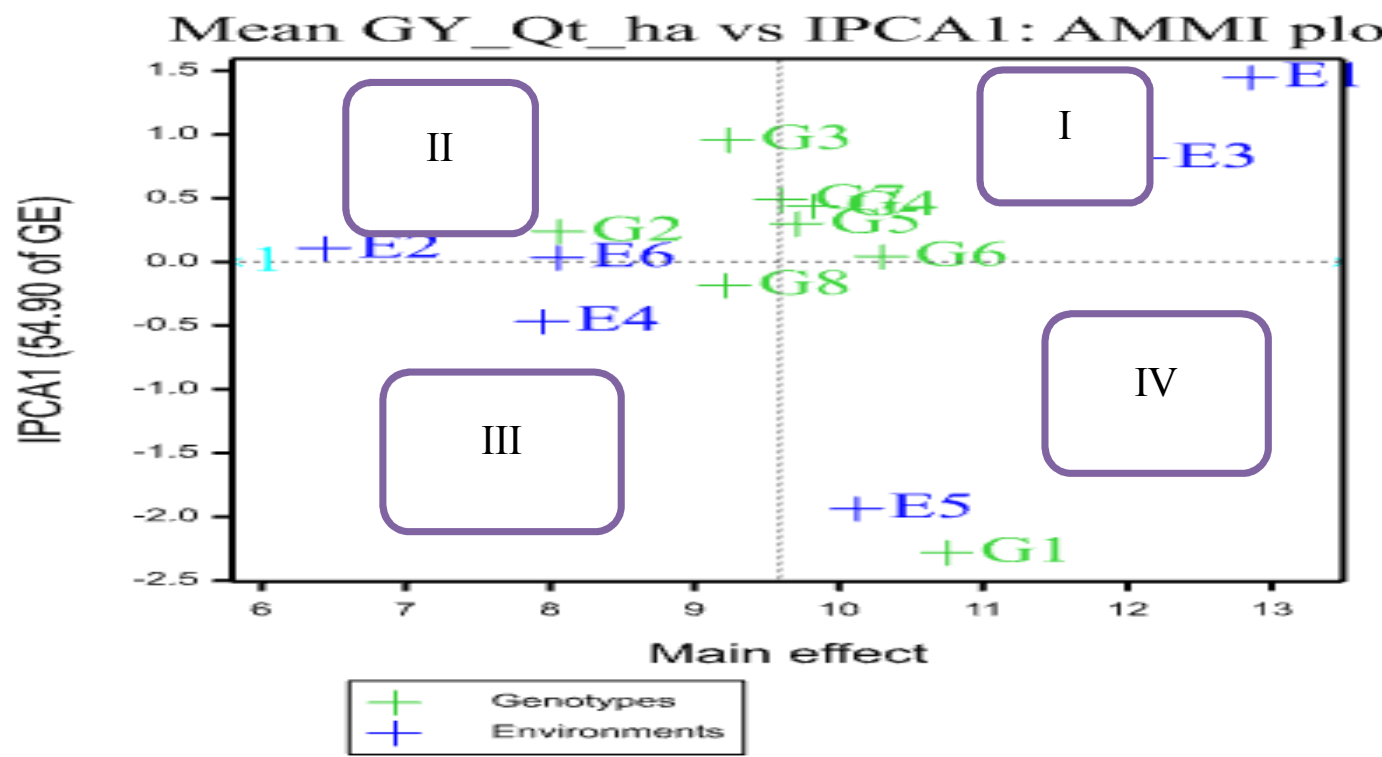

Genotype and Genotype by Environment interaction (GGE) bi-plot analysis

In GGE bi-plot (Figure 2), IPCA 1 and IPCA 2 explained $48.07 \%$ and $25.93 \%$, respectively, of groundnut variety by environment interaction and made a total of $74.00 \%$. The other study conducted on the same crop showed $81.8 \%$ total of IPCA $\mathrm{A}_{1}$ and IPCA 2 (Amare et al., 2014). Environments and genotypes that fall in the central (concentric) circle are considered as ideal environments and stable genotypes, respectively (Yan, 2002). A genotype is more desirable if it is located closer to the ideal genotype. Thus, using the ideal genotype as the center, concentric circles were drawn to help visualize the distance between each genotype and the ideal genotype. Therefore, the ranking based on the genotype-focused scaling assumes that stability and mean yield are equally important (Ezatollah et al., 2011). Fig. 2 revealed that G6 (Werer 962), which fell into the center of concentric circles, was ideal variety in terms of higher yielding ability and stability, compared with the rest of varieties. In addition, G1 located on the next concentric circle, may be regarded as desirable varieties. An environment is more desirable and discriminating when located closer to the center circle or to an ideal environment (Naroui et al., 2013). In the present study, E4 and E6 were the most discriminating and representative environments followed by E5 (Fig.3). E1was were nondiscriminating and less representative sites. This implied that, varietal stability could be challenged not only due to the change in the test environment but also due to differential response of tested varieties per environment.
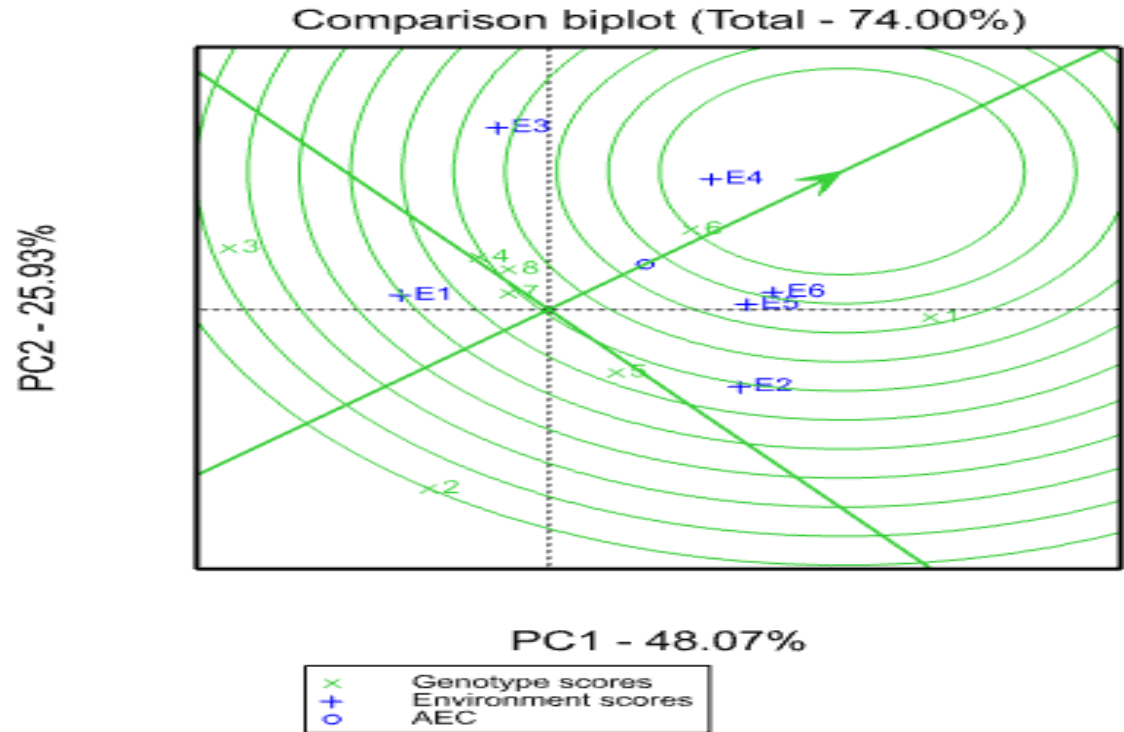

Fig. 2. The vector view of the GGE bi-plot based on environment focused scaling for environments to show relationship among testing environments.

$\mathrm{G}$ and $\mathrm{E}$ letters stand for genotypes and environments respectively. 
GGE bi-plot based on genotype-focused scaling for comparison of genotypes for their yield potential and stability

Figure 3 provides the summary of the interrelationships among the environments. The varieties that connect the bi-plot origin and the markers for the environments are called environment vectors. The angle between the vectors of two environments is related to the correlation coefficient between them. The cosine of the angle between the vectors of two environments approximates the correlation coefficient between them (Dagnachew et al., 2014). Based on the angles of environment vectors, the six environments are grouped in to two groups. Group one includes E1 and E3 and Group two involve E2, E4, E5 and E6. For instance, the smallest angle between E1 and E3 is implying that there are the highest correlations between them. The angle between E1 and E2; E3 and E2 are bigger than others showing the poor correlation between them (Figure 3). Two criteria are required to suggest existence of different mega-environments. First there are different winning genotypes in different test locations. Second, the between-group variation should be significantly greater than the within-group variation, common criteria for clustering. Dividing the target environment into different mega-environments and deploying different genotypes in different mega-environments is the best way to utilize GE interaction.

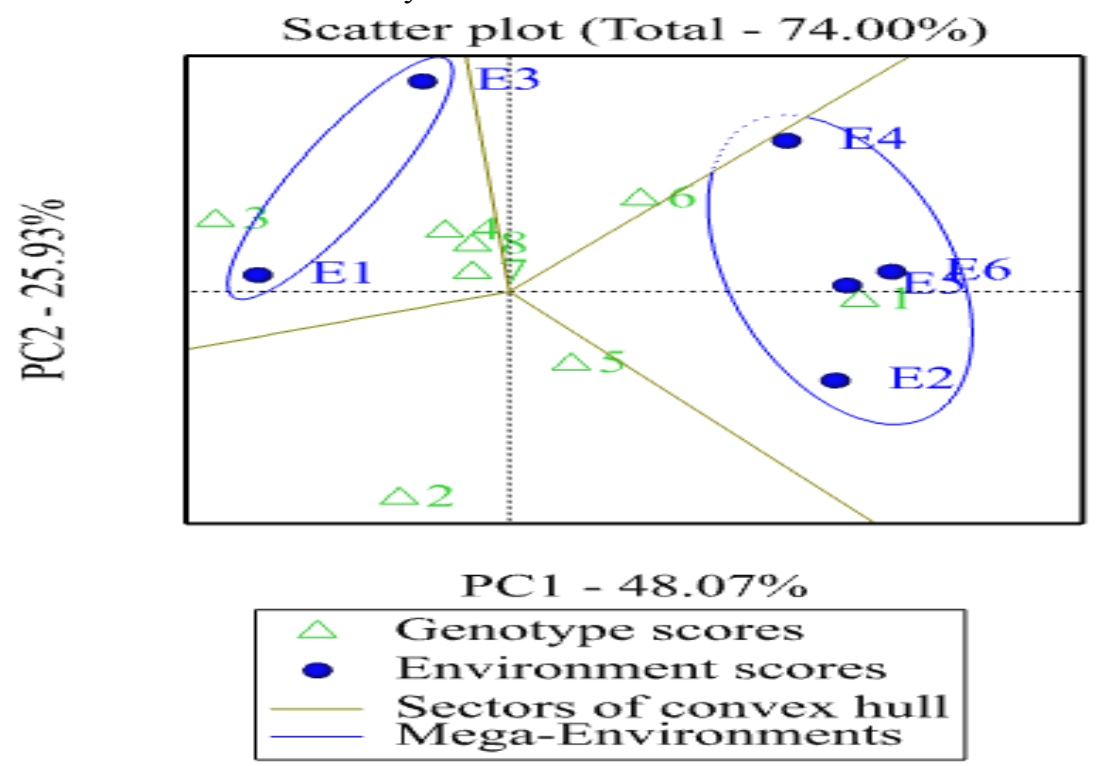

Fig. 3. GGE bi-plot based on genotype-focused scaling for comparison of genotypes for their yield potential and stability

\section{Summary and Conclusion}

Analysis of variance find out Environment and Genotype for seed yield showed statistically highly significant differences $(\mathrm{P}<0.01)$ indicating the presence of genetic variation and possible selection of high yielding and stable varieties. The average environmental seed yield across varieties ranged from the lowest of 6.44 Qtha $^{-1}$ at E2 (Erer 2017 ) to the highest of 12.85 Qtha $^{-1}$ at E1 (Fadis 2017), with a grand mean of 9.59 Qtha $^{-1}$. AMMI analysis of variance for Seed yield of eight groundnut varieties tested in six environments showed that environments, varieties and their interaction effects were significantly different $(\mathrm{P}<0.01)$. The environment modeled significant effect, which explained $48.67 \%$ of the total variation indicating the existence of a considerable amount of deferential response among the varieties to changes in growing environments and the differential discriminating ability of the test environments. Accordingly, Bulki and Babile2 were most stable and Werer961 and Baha Jiddu were the most unstable. The stability and high yielding ability of the varieties has been graphically depicted by the AMMI biplot. Environments E3 (Fadis 2018) and E1 (Fadis 2017) relatively showed high IPCA scores, contributed largely to GEI. These environments were favorable for high yielding varieties based on mean yield as they had more than the grand mean. The variation of yield for each variety was significant at different environments. Varieties G1 (Bulki), G6 (Babile2) and G4 (Werer962) were specifically adapted to high yielding environments. G2 (Shulamiz) was the most unstable variety and also adapted to higher yielding environments. G1 (Bulki) was more stable in comparison to other varieties. Generally, Fadis was the most favorable environment for ground nut production with maximum mean of yield potential. In GGE bi-plot; IPCA 1 and IPCA $_{2}$ explained $48.07 \%$ and $25.93 \%$, respectively, of groundnut variety by environment interaction and made a total of $74.00 \%$. GGE bi-plot revealed that G6 (Werer 962), which fell into the center of concentric circles, was ideal variety in terms of higher yielding ability and stability, compared with the rest of varieties. In addition, G1 located on the next concentric circle, may be regarded as desirable varieties. In the present study, E4 and E6 were the most discriminating and representative environments followed by E5. E1 was non-discriminating and less representative sites. 


\section{Reference}

Amare Kebede and Adisu Getahun, 2017. Adaptability and Stability Analysis of Groundnut Genotypes Using AMMI Model and GGE-biplot. Journal of Crop Science and Biotechnology 20 (5): 343 349

Dereje Assefa,Muez Teare and Helge Skinnes, 2012. Natural Occurrence of Toxigenic Fungi Species and Aflatoxin in Freshly Harvested Groundnut Kernels in Tigray, Northern Ethiopia. Journal of the Dry lands 5 (1): $377-384$

Hagos T, and Fetien A. 2011. Additive Main Effects and Multiplicative Interactions Analysis of Yield Performance of Sesame Genotypes across Environments in Northern Ethiopia. Journal of the Dry lands 4(1): 259-266

Yan W, Rajcan I, 2002. Biplots analysis of the test sites and trait relations of soybean in Ontario. Crop. Science. 42:11-20.

Ezatollah F, Hassan Z, Reza M. 2011. Evaluation of phenotypic stability in chickpea genotypes using GGE-Biplot. Annals of Biological Research 2 (6): 282-292.

Sunday Clement O. Makinde, Omolayo Johnson Ariyo, and Raphael Ilesanmi Akinbowale, 2013. Assessment of groundnut performance in different environments using Additive Main effects and Multiplicative Interaction (AMMI) model. Canadian Journal of Plant Breeding. -1(2):60-66 